A New Look at Child Health

M. Joseph and R. C. Mac Keith. Pp. $x+124$. London: Pitman Medical. 1966. 15s.

This little book by two London paediatricians paints a picture of the state of child health in Britain to-day which is probably as accurate a representation as is possible from one viewpoint. Inevitably it has a London bias and some of the ills of paediatrics described are peculiar to the metropolis, being avoided by better management in the great regional centres. Nevertheless, most of the authors' credo will be acceptable as their own to paediairicians throughout the country. In looking to the future, the sights are set high - perhaps unrealistically high-but they give the thoughtful paediatrician a glimpse of a paediatric Utopia to aim at.

In the opening chapters, the nature and problems of child health are described, and if the claims made for paediatrics and paediatricians are at times inflated, they are exaggerated for the sake of emphasis. In comparing paediatric attitudes with those of general medicine, however, the authors do less than justice to the development of social medicine. They seem to forget that, whereas the academic Department of Child Health comprises both hospital and social paediatrics, these two aspects of medicine are represented in most medical schools by two separate Departments-Medicine and Social Medicine. While the former may be preoccupied with hospital medicine, the latter shares with Child Health a broad interest in community and preventive medicine.

The authors go on to describe the work of the general practitioner in paediatrics, of the hospitalbased paediatrician, and of the preventive services for children. Current thought about theories and practice of child care in hospital receives detailed consideration and a short survey is made of paediatric research in progress and needed. A chapter on administration deals concisely with the organization of health services for children in England. The chapter on education is perhaps least satisfactory, but it could hardly be expected that teachers in a London hospital could adequately present the ferment of new ideas and the variety of experiments in undergraduate teaching centres in other parts of the country. Many of the innovations suggested are standard practice elsewhere and it is doubtful if it is true of many medical schools outside London that "most students first hear about percentiles and standard deviations during their paediatric appointment". Nevertheless, it must not be forgotten that half the undergraduate medical schools in the country are in the south-east and that none has a chair of Child Health, so that there is justification for emphasizing the lowest prevailing standards, at the risk of giving a misleading impression of British paediatrics as a whole. This is not to say that all is well elsewhere-far from it. As Joseph and Mac Keith point out, what paediatrics is and does-let alone what it could do-are unknown to many, even in the medical profession. There is too little collaboration and co-operation between the many services concerned with children, and too little understanding of the needs of children by the boards and committees which decide policy and make plans. Many excellent recommendations are made by the authors, but it is to be feared that too few will be implemented, at least in the forseeable future. If every administrative officer and board chairman would "read, learn and inwardly digest" this book, the children of to-morrow might be better served than they are to-day, or indeed are likely to be as things are developing in some areas.

Perhaps the least encouraging aspect of the future of Child Health in this country is the dearth of young paediatricians with a thorough grounding and real interest in the aims and outlooks of social and preventive paediatrics. Too many of those in training are intent on being hospital doctors for children and it is doubtful whether, if given more time to acquire wider understanding of child life as recommended by Joseph and Mac Keith, they would use it in this way. The suggested recruitment of senior medical registrars to paediatrics may help to make up the deficit in numbers but will not improve the quality. Perhaps if all students, undergnaduate and postgraduate, could be persuaded to read this book, they might succumb to the fascination of the study of Child Health, and learn that it is a university discipline of wide social and academic significance as well as a life's work of absorbing interest.

\section{The Spiral After-Effect}

Harry C. Holland. Pp. xii +128 , illustrated Oxford: Pergamon Press. 1965. 35s.

The perception of apparen $i$ reverse movement of a stationary object immediately after switohing the gaze from a moving or apparently moving object is known as the after-effect of apparent movement. This illusion has been investigated sporadically over the last century; more recently with specific reference to the perception of such phenomena as moving and stationary spirals. Dr. Holland has produced a clearlyo written objective monograph which summarises the historical field in relation to current work including his own studies. The phenomena is found to varye with the nature of the stimulus and the individual.? Individual variability has been found to depend on such factors as personality including rigidity and suggestibility characteristics, age, intelligence, motivation within the experimental situation and the immediate level of anxiey. Clearly, with so many factors influencing it, it is difficult to apply clinically, but attempts have been made to use it as a test for brain damage and its localization and for drug intoxication.

There must still remain doubts as to whether the spiral after-effect will ever prove a stable enough characteristic of the individual for it to be useful as a diagnostic aid. Meanwhile the current status of the subject has been enthusiastically but fairly presented by the author. A few spelling mistakes (e.g. psychological for physiological, 2nd word, para. 4 on page 100 ) and the relatively high price of the book a re handicaps.

\section{Spatiocardiography. Textbook and Atlas}

Vilem LAUFBerger. Pp. 183, illustrated. London: H. K. LEWIS. 1965. 50s.

The foundations of vectorcardiography were laid by Einthoven at the turn of the century. Progress has been disappointingly slow despite revolutionary advances in electronic technique. There are many reasons for this: the apparatus is complex and costly; the theoretical justification of the method requires solid geometry, an unfamiliar branch of mathematics, and clinicians are reluctant to move away from scalar electrocardiography and to learn a new discipline. The author has met many of these objections in this book, but there is not sufficient clinical material to 